impossible to distinguish the colors, the following points may be demonstrated:

I. The small white circle $(W)$ is invisible when fixated directly, but is clearly visible when any point on the frame of the mat is fixated.

2. When $W$ is fixated the patterns immediately adjacent are less clear in brightness and outline than similar patterns lying nearer the periphery.

3. The foveal area tends to be filled in by imagery of the surrounding surfaces. It is only after attention has been directed to the fact that it is observed that the pattern covering the foveal area is less distinct than the peripheral areas. In this respect the demonstration gives an indication of how the blind spot of the retina is filled by imagery in daylight vision.

4. The pattern of the entire mat will have changed to a striped effect whereas in daylight the patterns will appear quadrilateral in character and much less definite.

5. When the illumination is increased so that the colors appear, but the outlines of the pieces are not yet clearly defined, the relief effect of the colors is very pronounced. The mat will appear to be made of mosaics which seem to be at different distances. Where the observer does not know that the surface is actually flat this relief effect is of course much more vivid.

The mat is also useful for class demonstrations in the perceptual processes. By changes in the direction of attention the colored squares can be grouped into a large number of different patterns. For those persons whose affective life is influenced by color tones this mat presents possibilities of affective experience hardly realized by the most ambitious cubist paintings.

Ohio State University

A. P. WEISS

\title{
ON THE COMPUTATION OF THE STANDARD DEVIATION
}

The method of computing the standard deviation which will be described here is so simple, and is so direct an application of the common Short-Cut method that it seems unlikely the method has not been suggested before. A survey of the manuals on statistical methods has led the writer to believe that the procedure to be described is not widely used, although attention may have been previously called to it. That the method is of great 
value is shown by the fact that the labor of computing the standard deviation becomes far less than that of computing the average deviation.

Any deviation is equal to the score minus the arithmetic mean. That is,

$$
\begin{aligned}
d & =x-M, \\
x & =d+M, \\
x^{2} & =d^{2}+2 d M+M^{2} .
\end{aligned}
$$

Now sum for all cases.

$$
\begin{aligned}
S\left(x^{2}\right) & =S\left(d^{2}+2 d M+M^{2}\right) \\
& =S\left(d^{2}\right)+2 M \cdot S(d)+n M^{2} .
\end{aligned}
$$

Since deviations are measured from the arithmetic mean,

and therefore

$$
S(d)=0
$$

Divide by $n$

$$
S\left(x^{2}\right)=S\left(d^{2}\right)+n M^{2} .
$$

$$
\frac{S\left(x^{2}\right)}{n}=\frac{S\left(d^{2}\right)}{n}+M^{2} \text {. }
$$

Since $\left[S\left(d^{2}\right)\right] / n=$ standard deviation squared, the square of the standard deviation equals (sum of the scores squared) $/ n$ minus the square of the arithmetic mean.

In actual work, if an adding machine that will carry two columns of figures is used, the following procedure is suggested.

Print in the first column the score and in the second column the square of the score. Thus

$$
\begin{array}{lcc} 
& 5 & 25 \\
& 6 & 36 \\
& 2 & 4 \\
& 8 & 64 \\
& \frac{7}{28} & \frac{49}{178} \\
\text { Sum } & 5.6 & 35.6 \\
\text { Average } & 5.6 & \\
\text { Subtract } M^{2} & & \frac{31.36}{4.24} \text { which is the standard deviation squared. }
\end{array}
$$

Extract the square root

2.05 which is the standard deviation.

This method has two advantages over the common method of 
computation. (I) It is unnecessary to make a subtraction for each score. (2) The standard deviation may be found correct to any desired number of decimal places, simply by carrying the average to that number of places.

University of Chicago

Beardsley Ruml

\section{BOOKS RECEIVED}

MeAd, C. D. The Relations of General Intelligence to Certain Mental and Physical Traits. New York: Teachers College, 1916. Pp. II7. \$r.50.

Woody, C. Measurements of Some Achievements in Arithmetic.

New York: Teachers College, 1916. Pp. 63. \$r.00.

McDonald, R. A. F. Adjustment of School Organization to Various Population Groups. New York: Teachers College, 1916. Pp. 145. \$1.50.

Trabue, M. R. Completion Test Language Scales. New York: Teachers College, I9I6. Pp. II8. \$I.50.

Thorndike, E. L., McCall, W. A. \& Chapman, J. C. Ventilation in Relation to Mental Work. New York: Teachers College, 1916. Pp. 83. \$I.00.

Dearborn, G. V. N. How to Learn Easily. Boston: Little, Brown, 1916. Pp. $x+227$. \$r.oo.

Heathcote, C. W. The Essentials of Religious Education. Boston: Sherman, French, r9I6. Pp. 290. \$1.50.

Binet, A. \& Simon, T. The Development of Intelligence in Children. (Trans. by E. S. Kite.) Vineland, N. J.: The Training School, 1916. Pp. 336. \$2.00.

Binet, A. \& Simon, T. The Intelligence of the Feeble-Minded. (Trans. by E. S. Kite.) Vineland, N. J.: The Training School, 1916. Pp. 328. \$2.00.

Talmey, B. S. Love: A Treatise on the Science of Sex-Attraction. New York: Practitioners' Publ. Co., 19r6. 2nd ed. Pp. $x+$ 438. \$4.00.

WhIte, W. A. Mechanisms of Character Formation; An Introduction to Psychoanalysis. New York: Macmillan, I9I6. Pp. 342. $\$ 1.75$.

Adams, H. F. Advertising and Its Mental Laws. New York: Macmillan, 1916. Pp. xi + 333. \$1.50. 